\title{
ТЕЛЕМЕДИЦИНА: ОПЫТ ПРАКТИЧЕСКОГО ИСПОЛЬЗОВАНИЯ
}

\author{
Юдицкая Т.А., Власенко Н.Ю., Юнгман Н.В., Каргаполова К.И., Канычева Н.П., Щукина Е.О.
}

ФГБОУ ВО «Омский государственный медицинский университет» Минздрава России; БУзОО «Областная детская клиническая больница», Омск

АКТУАЛЬНОСТЬ: в связи с повышением потребности в медицинских услугах увеличивается нагрузка на медицинских работников и все сложнее осуществлять надлежащий медицинский контроль. Внедрение телемедицины делает более доступной высокотехнологичную медицинскую помощь и консультации ведущих специалистов.

ЦЕЛЬ: изучить потребность Омской области в консультациях детей с эндокринной патологией на Федеральных базах. Проанализировать опыт внедрения результатов консультаций в клиническую практику.

МАТЕРИАЛЫ И МЕТОДЫ: В ИсследОВаниИ прИняЛИ Участие 30 детей с эндокринной патологией в возрасте с рождения до 18 лет, которые были проконсультированы очно и заочно, или получили направление на госпитализацию. Проведен анализ направительных документов на консультации и выписок из Федеральных центров.

РЕЗУЛЬТАТЫ И ОБСУЖДЕНИЕ: В ОМской области детское население составляет 418 тыс. человек, госпитализированных пациентов с эндокринологической патологией около 1100 в год, из них 30 пациентов получили телемедицинские консультации за 2019 год.

Эндокринологическая служба Омской области всегда активно сотрудничала с Федеральными базами г. Москва и Санкт-Петербург (консультации сложных пациентов, направления на госпитализацию пациентов в том числе для хирургической или лучевой терапии). С 2017 г. в соответствии с приказом МЗ РФ № 965н «Об утверждении порядка организации и оказания медицинской помощи с применением телемедицинских технологий» это получило официальный статус.

С внедрением телемедицины у нас появилась возможность привлечения для консультации сразу многих специалистов (несколько Федеральных баз) и определения более быстрой и правильной маршрутизации пациента. Благодаря использованию телемедицины в 2019 году нами было отправлено на стационарное лечение в ФГБУ «НМИЦ эндокринологии» Минздрава России 8 пациентов; 1 консультация проведена с ФГБУ «НМИЦ акушерства, гинекологии и перинатологии имени академика В.И. Кулакова», в РДКБ госпитализировано 3 пациента (без сахарного диабета). Для установки инсулиновой помпы в Москву было отправлено 10 пациентов (ФГБУ «НМИЦ эндокринологии» Минздрава России и РДКБ).

Мы активно используем возможности проведения молекулярно-генетического обследования в ФГБУ «НМИЦ эндокринологии» Минздрава России за счет средств федеральной программы «Альфа-эндо», что тоже требует получения согласия от ведущего специалист по данному направлению. В 2019 году отправлены биообразцы 7 детей, в 3 случаях были выставлены диагнозы: врожденный гиперинсулинизм, гестационный диабет, нефрогенный несахарный диабет. Благодаря телемедицине появилась возможность быстро изменить тактику терапии в соответствии с данными медико-генетического исследования. Мы также получили первый опыт терапии данных пациентов: с нефрогенным несахарным диабетом (гипотиазид, индометацин), врожденным гиперинсулинизмом (Диазоксидом). Информационные технологии выступают, как инструмент персонализированной медицины.

ЗАКЛЮЧЕНИЕ: внедрение телемедицинских технологий в работу детской эндокринологической службы повышает доступность медицинской помощи. Ускорилась диагностика (в том числе с помощью молекулярно-генетического исследования), и сократились сроки от дебюта заболевания до начала патогенетической терапии.

КЛЮЧЕВЫЕ СЛОВА: телемедицинские консультации; дети; персонализированная терапия. 